\title{
Muhasebe Bilgi Sistemi ve Kaynak Kullanım Muhasebesinin Yönetim Kararları Üzerindeki Etkisi
}

\author{
DOI: 10.26466/opus.833494 \\ * \\ Kadir Aydin * \\ * Dr. Öğr. Üyesi, Adıyaman Üniversitesi, Adıyaman/Türkiye \\ E-Posta: aydinkadir02@yahoo.com \\ ORCID: $\quad \underline{0000-0002-2437-8118}$
}

\section{Öz}

Şirketlerde, tüm organizasyonel faaliyetlerden verilerin toplanması, izlenmesi, sinfflandirlması, özetlenmesi prosedürleri, finansal olaylar görüntülemek ve değgerlendirmek gibi işlemler Bilgi Teknolojisi tarafindan yürütülür. Muhasebe yönetim sisteminde, bilgi teknolojileri ve muhasebe kayıtların kullanan yöneticiler, işlemsel muhasebe sistemi bilgileri ve iç finansal raporlama sistemi ile operasyonları hakkında bazı bilgiler toplarlar. Muhasebe bilgi sistemi (MBS), yöneticilerin maliyetfayda analizi ile kontrol edilebilir olayları, kontrol edilemeyen olaylardan ayırt etmesine olanak tantr. Muhasebe bilgi sistemi, yönetim bilgi sistemi teknolojisini oluşturan ur ve otomatik bir bilgi sistemidir. Organizasyonun her şubesinde finansal faaliyetler bulunur. Yapılan çalışmada, muhasebe bilgi sistemi ve yönetim bilgi sistemi ile kavramsal olarak ilgilenir. Son zamanlarda imalat teknolojisi ve üretim modellerine göre maliyet yapılarının ve modellerinin üretim yapan firmalar için ihtiyaç olarak değerlendirildiğini ifade edilir. Nedensel açıdan bakıldığında, geleneksel sistemlerin maliyet ve kontrol muhasebesi ile kullanılması, cari için yeterli veya uygun değildir. Kaynak tüketim muhasebesi, 2000'li yılların başından itibaren gündeme gelen yeni bir yaklaşımdır. Bu yaklaşım, Faaliyet Tabanlı Maliyetleme'nin avantajların kullanan ve Alman Maliyet Muhasebesi'nin kaynaklara bakış açısıyla entegre edilen bir yaklaşım olup, maliyetlerin temelinin kaynaklar olduğunu kabul eder. Kaynak tüketim muhasebesini diğer yöntemlerden ayıran unsurlar; şey atıl kapasitesinin izlenebilmesi, amortisman hesaplamasinda yerine koyma maliyetini kullanması ve yönetim kararlarında etkili olan Katkı Marjı Gelir Tablosu'nu kullanmasıdır. Bu çalışmada öncelikle Kaynak Tüketim Muhasebesinin ortaya çıkışı, tanımı ve özelliklerine yer verilerek, aşamaları belirtilmiştir.

\section{Anahtar Kelimeler: Kaynak Tüketim Muhasebesi (KTM), Faaliyet Tabanlı Maliyetleme} (FTM), Bilgi Sistemi Muhasebesi 


\title{
Influence of Accounting Information System and Resource Using Accounting on Management Decisions
}

\begin{abstract}
Procedures of data gathering, observing, categorizing and summing up operational or organizational activities, screening financial activities and their evaluations are all operated by the information Technologies in the companies. In a specific field, in accounting management system, managers using information technologies and accounting records gather data on their operations with transactional accounting system and internal financial reporting system. Accounting Information System (AIS) assists the managers with cost-benefit analysis to differentiate between controllable and uncontrollable activities or operations. Accounting information system composes management information technology and it is an automated information system which is deployed in all braches of an organization. In this study, conceptual relations between accounting information system and management information system are taken under consideration. It is recently acknowledged that cost structures and models according to productions technology and production modeling are a necessary tool for manufacturing companies. It is because of that conventional systems using cost and control accounting is not sufficiently effective or just not applicable for current company liabilities. Since early years of 2000s, recourse expenditure accounting is a new approach to accounting. This approach is based on the idea that core of costing is recourses, which takes advantages of activity-based-costing and is integrated with German perspective of cost accounting. What makes this approach distinctive from others are that it can trace spare capacity, it uses substitution cost in amortization, and it uses additional income margin table which is crucial in management decisions. This study seeks to explain emergence, definition and features of Resource Expenditure Accounting and its development phases.
\end{abstract}

Keywords: Resource Expenditure Accounting (REA), Activity-based-Costing (ABC), Information System Accounting 


\section{Giriş}

Günümüzde hızla artan rekabetle birlikte üretim süreçleri ve endüstrilerin teknolojileri si de gelişmektedir. Geleneksel bakış açıları yerine, çağdaş yaklaşımlara yönelimler artmıştır. Çağdaş yaklaşımlar, maliyet ve yönetimde ön plana yerleştirilmiştir ir. Bu yöntemlerden herhangi biri, Faaliyet tabanlı maliyetleme, tam zamanında üretim, yalın muhasebe, hedef maliyetleme gibi yaklaşımlar çağdaş bu yaklaşımlardan bazılarıdır. Bu yaklaşımlara 2000'li yıllarda Kaynak Tüketim Muhasebesi de ilave edilmiştir.

Yönetim Muhasebesi Enstitüsü (IMA) tarafından 2003 yılında üstlenilen organizasyonlarda maliyet kontrolü incelemesi aşağıdaki gibidir:

- \%80'i geleneksel maliyet sistemini kullandığını,

- \%77'si karar destek bilgisinden memnun olmadığını,

- $\quad \% 80$ 'i değişimin öncelik olmayacağını belirtmişlerdir.

$\mathrm{Bu}$ bulgular, şirketlerin fikirlerini yansıtırken, mevcut yaklaşımların eksiklikleri nedeniyle yeni yaklaşımların kullanılmasının gerekliliğini ifade eder. Kaynak Tüketim Muhasebesi; kaynağın, maliyetin temeli olduğu görüşüne dayalı olarak Alman Maliyet Muhasebesi ve Faaliyete Dayalı Maliyetlemenin entegre edilmesiyle nden gelişmiştir. Bu yöntem, maliyetleri sabit ve göreceli maliyetler olarak sinıflandırarak $n$ atıl kapasitenin izlenmesine olanak sağlar. Böylece operasyonel performansın iyileştirildiği de vurgulanır.

Bilginin işletme yöneticilerinin verdiği kararlarının karmaşıklığın belirlemesini tespit edip, bu karmaşıklı̆ 1 en aza indirgemesine ve anlamlı olabilmesi için; bilginin doğruluğu, tamlığı, zamanlılığı, ekonomikliliği ve sadeliği gibi özelliklere sahip olması gerekir. Bir bilgi sisteminin verimli olup olmadığı, üretilen bilginin önemi ile yakından ilgilidir. bağlantılıdır.

Finansal muhasebe bilgisinin işlevi kısaca; işletmenin halka açılma performansına ilişkin bilgileri ve finansal pozisyonu, denetlenmiş finansal raporlarının kamuoyuna açıklanması, şirket muhasebesi ve dış raporlama sistemine yönelik bilgiler üretmesidir ir. Finansal muhasebe sistemi, doğrudan ve dolaylı olarak stoklar dahil gerçekleri sağlayarak izleme yapısını sağlar. Dahası, işletme sahibi ve yöneticilerinin farklı 
kişilerde toplanması nedeniyle finansal muhasebe sistemi, yatırım fırsatlarının değerlendirilmesi, insan ve finansal sermayenin akışını kolaylaştırması ve faaliyet güçlügünün önündeki engellerin azalması hususunda da bilgi sağlar.

\section{Muhasebe Bilgi Sistemi'nin İşlevi ve Tanımı}

Tüm alt sistemlerdeki parasal akımının izlenmesine izin veren sistem, Muhasebe Bilgi sistemidir. Muhasebe, fonksiyon olarak; finansal hareketliliği sağlayan işleyişin ve oluşumların dokümantasyonunu, sınıflandırmasını, özetini ve anlaşılır bir analizini sağlar. Günümüzde muhasebe, sadece bir izleme yöntemi değil; stratejik planların tasarlanması planlanması için bir izleme mekanizmasıdır ve veri olarak kullanılmaktadır. Muhasebe raporları, şirketlerin faaliyet sonuçlarını doğru bir analiz yöntemi olarak değerlendirilir (Tutar, 2010, s.313).

Ayrıntılı muhasebe bilgi sistemi, genel veya finansal muhasebe, maliyet ve yönetim muhasebesi gibi geleneksel muhasebe sistemlerini içerir. Muhasebe bilgi sistemi, "işletme faaliyetlerini planlamak, kontrol etmek ve yönetmek amaciyla bilgi kullanıcılarının gereksinim duydukları bilgileri sağlamak için verileri ve mali nitelikli işlemleri süreçleyen ve onlara sunan bir bilgi sistemi bilgi sistemi" şeklinde tanımlanabilir. Muhasebe bilgi sistemi, günümüze kadar en iyi biçimde geliştirilmiş olan ve hala uygulanan bilgi sistemidir (Şahin, 2007, s.33).

Finansal Raporlamaya İlişkin Kavramsal Çerçeve'de, muhasebe bilgi sistemi tarafından sağlanan finansal verileri dahil etmek için yararlı olması gereken tutarlılık özellikleri aşağıdaki şekilde belirtildiği gibidir miştir (Kamu Gözetimi Kurumu, 2018, s.11):

- Temel olarak niteliksel özellikler; ihtiyaca uygunluğu, önemliliği ve gerçeğe uygun sunumu

- Destek sağlayı niteliksel özellikler; kıyaslanabilirlik, anlaşılabilirliği yüksek olması, zamanında yapılan sunum ve doğrulanabilirlik.

Kurumsal kaynak planlaması olarak isimlendirilen bilgisayar yazılımları, muhasebe bilgilerinin üretilmesinde kullanılır. Ortak bir veri tabanında toplanan kurumsal kaynak planlamasıyla işletme fonksiyonları ve bilgi sistemleri, bilgi ihtiyacı olduğunda hali hazırda 
üretilmiş olan bilgi raporlarına kolay bir şekilde erişim sağlar. İşlemde kullanılacak olan kaynak planlaması yapısı üretilecek olan muhasebe bilgisinin kalitesini etkiler (Acar, 2011, s.16). Kurumsal kaynak planlaması, bir işletmedeki tüm alt bilgi sistemlerini sadece tek bir yazılım ve veri tabanı altında toplar. İşletmelerin ürettikleri bilgileri ve işletmedeki tüm alt sistemleri muhasebe bilgi sistemi ile bütünleştirir (Türel, 2018, s. 20).

İşletmelerin pazar performansını en üst düzeylere çıkarabilmesi için kaliteli bilginin sağlanması gerekir. Kurumsal kaynak planlanması olarak isimlendiren bilgisayar yazılımları, muhasebenin kayıtlarının işlenmesinde kullanılır. İş fonksiyonları ve veri yapısı hakkındaki veriler kurumsal kaynak planlanması için paylaşılan veri tabanında toplanır. Bu durum, bilgi ihtiyaçları ortaya çıtığında üretilen bilgi raporlarına hızlı bir erişimi mümkün kılar. Oluşturulacak hesapların tutarlılığını etkileyen faktör; organizasyonel kaynak planlama sistemidir (Acar, 2011, s.16).

Kurumsal işlemlerde, muhasebe bilgi sistemi üç bilgi kategorisi içerir. Üç bilgi kategorisinin içeriği şu şekildedir: bu bilgileri içerir; İşletmenin dışındaki kullanıcılara sunulan bilgiler, işletmenin içerisindeki kullanıcılara sunulan bilgiler ve değerlendirme yapılması için gerekli bilgilerdir. Müşteri, müşteri listesi, satıcı hesabı, tedarikçi listesi, geçmiş yılların finansal raporlama sonuçları, kredi raporları ve banka ekstreleri gibi bilgiler işletme muhasebe bilgi sistemine dahil edilir. Bu sistemin kuruluş amacı, muhasebe bilgi sistemini geliştirerek parasal hareketlerin izlenmesini sağlamaktır. Bu sistem, gelirler, siparişler, fiyatlar, mali yapı, bütçe ve raporlama ve idari muhasebe gibi süreçleri içerir ve özellikle mali yöneticilerin karar vermesine yardımcı olabilecek bilgileri sağlamak ve koordine etmek için kullanılır. Organizasyonlarda aşağıdaki alanlarda muhasebe bilgi sisteminden yararlanılır (Tutar, 2010, s.315):

a) Verilerin işlenmesi b) Kullanıcıların ihtiyaçları doğrultusunda üretilmiş bilgileri sağlamak c) Mali işlemleri ve bunlarla alakalı diğer verileri toplayarak muhasebe bilgi sistemine girmek d) Bilginin doğrulanabilir ve güvenilir bir ortamda üretilebilmesi amacıyla süreçlerin bütününü kontrol altında tutmak e) Muhasebe bilgi sisteminde kayıt altındaki verileri sorgulamak. 
Verileri muhasebe bilgilerine dönüştürmek için muhasebe bilgi sistemi; çeşitli farklı bireylerin bilgi ihtiyaçlarını tanımlamayı, ve fiziksel kaynakları ve diğer nesneleri entegre etmeyi amaçlamaktadır. Muhasebe bilgi sisteminin beş ana hedefi vardır: Verilerin bir araya getirilmesi, verilerin işlenmesi, veri tabanı, fabrika fonları, prosedürler, çalışan elemanlar, tedarikler ve kapital gibi olgularla birleşir. Organizasyonun yapısı, özellikleri ve faaliyet alanına bağlı olarak, muhasebe bilgi sistemi de değişir (Ömürbek, 2003, s.123).

İşletmelerin yönetiminde; muhasebe bilgi sisteminin önemi, çeşitli açılardan ele alınabilir. İyi bir şekilde tasarlanmış muhasebe bilgi sisteminin organizasyona katabileceği değerler aşağıda gösterilmiştir (Romney ve Steinbart, 2015, s.11):

- Kaliteyi üst düzeye çıkarır ve mal/ hizmet maliyetlerini düşürür.

- Verimliliği yükseltir.

- Bilgi paylaşımına destek olur.

- Tedarik zincirinin verimliliğini ve etkinliğini artırır.

- $\quad$ İç kontrol yapısını iyileştirir.

- Karar verme etkinliğini yükseltir.

\section{Muhasebe Bilgi Sisteminin Unsurları}

İşletmenin dillerinden birisi de muhasebe olarak belirtilir. $\mathrm{Bu}$ benzetmeye yönelik muhasebe yönetimi, kelime haznesinde kullanılan zekadır; yani bir bilginin aracıdır. Bir veriyi toparlama, tanımlama ve depolama yönetimi yerine; muhasebe bir bilgi üretimi, bağlantı ve değerlendirme süreci olarak ifade edilebilir. Ayrıca muhasebe bilgi sistemi, organizasyon hakkındaki karar veren kişilere bilgi üretmek için muhasebe ile ilgili tüm verileri ve diğer verileri derler, kayıt altına alır, depolar ve işler. Muhasebe bilgi sisteminin görevi; veri ve bilgileri toplamak, kaydetmek, işlemek, saklamak ve raporlamak olarak ifade edilir. Bir muhasebe sisteminin altı adet unsuru bulunur (Romney ve Steinbart, 2015, s.37). Bu unsurlar ; sistemi kullanan insanlar, organizasyon ve ticari faaliyetlerle ilgili veriler, veri toplamak, işlemek ve depolamak için kullanılan prosedür ve talimatlar, verilerin işlenmesi için kullanılan yazılım, muhasebe bilgi sistemi içerisinde kullanılan bilgisayarlar, ağ iletişim aygıtları ve çevresel donanımlar olmak üzere 
bilgi teknolojisi alt yapısı ve muhasebe bilgi sistemi verilerini koruyan iç kontroller ve güvenlik önlemleridir.

Etkili bir muhasebe sistemi geliştirirken ve işletirken, muhasebe sisteminin unsurları ve bu unsurlar arasındaki ilişki hakkında bilgi sahibi olunması gerekir. Bu anlamda sistemin işlemesini sağlayan fiziksel ve mantıksal unsurlar ve anlamlı ilişkiler muhasebe bilgi sisteminin bileşenleri olarak ifade edilir. Muhasebe veri sisteminin işleyişi bu nedenle ancak sistem elemanları işlevlerini yerine getirdiği takdirde mümkündür. Bu nesneler iki başlık altında toplanabilir (Sevim, 2008, s.54):

Fiziksel Öğeler: Gözle görülen, maddi olan unsurlardır. Muhasebe bilgi sistemindeki fiziksel unsurlar; donanım, eleman (insan), yazılı raporlar, haberleşme/iletişim araçları, hesap planları ve muhasebe el kitabından oluşur.

Fiziksel olarak görülemeyen fakat önemli konumları olan bilgilerin işlenmesi, rapor edilmesi, iletilmesi süreçlerinde uygulamaları yönlendiren unsurlar, kavramsal öğeler olarak isimlendirilir. Kavramsal öğeler yasalar, ahlaki kurallar veya etik değerler, yöneticilerin yönergeleri ve muhasebenin temel kavramları, ilkeleri ve standartlarından oluşur.

Temel ve fiziksel öğeler (personel, iletişim araçları ve raporlar, donanım) muhasebe bilgi sisteminin işlevini karşılaması için gerekli olan unsurlardır. Bahsedilen fiziksel öğelere dair açılamalar aşağıda gösterilmiştir.

\section{Personel (İnsan)}

Muhasebe bilgi sisteminin bir parçası olarak çalışanlar, muhasebe bilgi sisteminin işlevlerini yerine getirir, verileri işler ve sisteme işlevsellik kazandırır. (Ertaş, 2016, s.77). Diğer sistemlerde olduğu gibi, muhasebe bilgi sisteminde temel öğe çalışanlardır, yani insanlar, muhasebe bilgi sisteminin kilit faktörüdür. Bilgi altyapısında, sürekli teknoloji büyümesi, insan faktörünün rolünü değiştirir. Buna rağmen, insanların önemi nadiren azalmakta, hatta yükselmektedir. Personellere ilişkin 
dikkat edilmesi gereken hususlar aşağıdaki gibi tanımlanabilir (Sevim, 2008, s.55):

- $\quad$ Eğitimli ve deneyimli personel

- Kişisel yetenek ve becerilere sahip personel

- Muhasebe servisinin iç örgütlenmesi

- Duygusal bir varlık olarak insan

- Personelin mesleki ahlaki

- Optimum personel sayisı

\section{Donanım}

Muhasebe bilgi sistemleri, teknolojik büyümeden en çok etkilenen sistemlerden biridir. İşletme genişledikçe, bir bilgisayara olan talebin de arttı̆̆1 görülür. $\mathrm{Bu}$ yenilikler, muhasebe personelleri için yetkinlik alanlarının dışında bilgi teknolojisi konusunda da temel bilgilere sahip olmasını gerekli kılmıştır.

Verileri veya bilgileri karar vermede kullanılacak bilgiye dönüştüren muhasebe bilgi sistemi; manuel hesaplama, mekanik (makinal1) hesaplama ve elektronik (bilgisayar tabanlı) hesaplama süreçlerini kullanır. Bu sistemlerde veri veya bilginin toplanması ve işlenmesinde daktilo, hesap makinesi, yazar kasa, bilgisayar, okuyucu, yazıcı gibi cihazlar kullanılır. Muhasebe bilgi sisteminde kullanılacak donanım, şirketin koşullarına, bilgi yönetimi işlemlerinin yoğunluğuna ve dolayısıyla kullanılan bilgi işlem türlerine göre değişiklik gösterebilir (Sürmeli, vd., 1998, s.61).

\section{Haberleşme Araçları}

İletişim araçları, veri veya bilgilerin tanınması, toplanması ve verilerin analizi bilgi işlem süreci için gerekli kayıtlardır. Bu kayıtlar, işlemler arasında yazışmayı sağlarken aynı zamanda kayıt, etiketleme, çoğaltma ve iletme işlemleri için gerekli kayıt ortamını oluşturur. Aynı zamanda iletişim yöntemleri de kanıt niteliğindedir. Finansal işlemler, iletişim yöntemleriyle zaman, maliyet, miktar, konum ve bireysel gibi çeşitli şekillerde tasvir edilir. İletişim yöntemleri çeşitli açlardan iki başlık altında açıklanabilir (Sevim, 2008, s.58): 
- Muhasebe Tekniğine Göre

- Düzenlenmesi Zorunlu ya da İhtiyari Olmasına Göre

Haberleşme kaynaklarını düzenlemek veya bir defter tutmak yasal bir gerekliliktir. Buna ek olarak, yasal olarak bağlayıcı olmayan haberleşme araçları, genellikle muhasebeye tahsis edilen değere ve işletme ölçeği gibi hususlara bağlı olarak kullanılır (Ertaş, 2016, s.77).

\section{Raporlar}

Sistemin belirlenebilen bir başka maddi ürünleri ise muhasebe bilgi sisteminin çıtıları olan raporlardır. İşletmenin içerisindeki kullanıcılara ve işletme dişındaki kullanıcılara bilgi sağlamak için kullanılır. Raporlar; iç raporlar ve dış raporlar olarak iki farklı gruba ayrıştırılabilir (Sürmeli, vd., 1998, s.61).

Muhasebe bilgi sisteminin çıktıları olan raporlar, sistemin hesaplanabilen veri sonuçlarıdır. İç ve dış bilgi kullanıcıları için tasarlandığından, raporları iç ve dış raporlar olarak ikiye ayrılabilir (Sürmeli, vd., 1998, s.61).

- İç Raporlar: Bilanço, bütçeler, maliyet raporları, stok kontrol raporlar1 vs.

- Dış Raporlar: Bilan,3ço, gelir tablosu, vergi iadelerine ilişkin raporlar, kredi kurumlarına verilen raporlar vs.

\section{Kaynak Tüketim Muhasebesi}

Kaynak tüketim muhasebesi modelinin birden çok tanımı vardır. Zhang ve diğerlerine göre (2011) kaynak tüketimi muhasebesi; Faaliyet tabanlı maliyetlemeyi Alman Maliyet Muhasebesi sistemiyle harmanlayan, fiyatların tahsisinde miktar tahminlerine dayanan bir yöntem, şirketlere karar vermelerinde yardımcı olabilecek karmaşık, sistematik ve genel bir maliyet kontrol sistemi olarak ifade edilebilir. Perkins ve Stovall'a (2011) göre bu, faaliyet tabanlı maliyetlendirme kaynak potansiyeli ve kaynak düzeyinde maliyet izlemeyi mümkün kılan neden-sonuç ilişkileri hakkında kapsamlı bilgi sağlayan bir görev analizi karışımıdır. 
Tutkavul'a (2016) göre, harcamaları azaltmak, gelirleri optimize etmek, şirketin karlı pazar potansiyelini geliştirmek ve son derece rekabetçi sektörlerde harika sonuçlar elde etmek amaciyla doğru bilgi üretmeye odaklanan bir yönetim muhasebesi stratejisi olarak tanımlamaktadır (Tutkavul, 2016, s. 110).

Kaynak Tüketim Muhasebesi Modeli, Alman Maliyet Muhasebesi Modelini faaliyet tabanl maliyetleme modeli ile entegre ederek 2000'lerin başında ortaya çıan daha güncel maliyetlendirme yöntemlerinden biridir. Anlaşılacağı gibi, hacim bazlı veya faaliyet bazlı maliyetlendirme modelleri, genel üretim maliyetini ücretlendirmek için kullanılır. En yaygın kullanılan model, basitliği nedeniyle hacim bazlı maliyetlemedir; ancak bu model, faaliyet bazlı maliyetlendirme modeline göre genel üretim maliyetlerinin birim maliyetlere yüklenmesinde çok doğru sonuçlar vermemektedir. Günümüzde dünyada karlılık için en kritik husus, birim maliyetlerin doğru ölçülmesi ve ortadan kaldırılmasıdır. Tüm $\mathrm{Bu}$ amaçla, hacim bazlı maliyetlendirme, faaliyet bazlı maliyetlendirme sonrasinda Alman maliyet muhasebesi modeli ve kaynak-tüketim muhasebesi modeli, dönemin koşulları için bir gereklilik olarak ortaya çıktığı ifade edilir.

Faaliyet tabanlı maliyetleme ve zamana dayalı faaliyet tabanlı maliyetleme modellerine nazaran Alman Maliyet muhasebesi modeline dayanan kaynak tüketim muhasebesi modelinin daha ayrıntılı bilgi sunduğu görülür (Özyapıc1, 2012, s.55).

\section{Alman Maliyet Muhasebesi}

1950'de Hans Georg Plaut, yeni bir maliyet muhasebesi modeli yaratmıştır. Bu model “Grenzplankostenrechnung" GPK olarak adlandırılmıştır. Ayrıca Prof. Dr. Paul Riebel tarafından ayrıca katkı payı muhasebesi adı verilen bir ölçüm modeli geliştirmiştir. Alman Maliyet Muhasebesi modeli, geliştirilen bu iki modelin entegre edilmesiyle oluşturulmuştur. Çoğu durumda, Alman Maliyet Muhasebesi modeli yönetim kararlarını destekler. Örneğin, üretim programlamaları, bir ürünü satın alma veya ithal etme kararı, fiyatlar, şirket içi geçiş fiyatlandırması vb. şeklinde olabilir. Buradan yöneticilerin kısa vadeli eylemlerini kolaylaştıran bir maliyetlendirme mekanizmasının var 
olduğu görülmektedir. Maliyet merkezleri, Alman maliyet muhasebesi modelinin temelini oluşturur. Bu maliyet merkezleri, ana maliyet merkezleri veya maliyet destek merkezleri olabilir. Maliyetler, maliyet merkezlerine gönderilirken sabit ve orantısal (değişken) maliyet olarak ayrılmaktadır. Burada maliyet merkezi muhasebesi fikri gelişmektedir. $\mathrm{Bu}$ model çok ayrıntılı olduğu için ndan, bilgi sisteminin çok sağlam olmasını lidır gerekli kılmaktadır (Aksu, 2013, s.176).

Alman Maliyet Muhasebesi modelinin amac1, tam maliyetler temelinde esnek maliyet bütçesindeki zayıflıkları ortadan kaldırmaktır. Maliyetlerin sabit ve orantısal (değişken) olarak bölünmesi, uyarlanabilir bütçeleme için bir maliyet yönetimi olarak kullanılır. Bu nedenle, şirket başarısını ölçmek ve kısa vadeli kurumsal yönetim kararlarını teşvik etmek için etkili bir modeldir. Örneğin kısa vadeli kararlarda, örneğin; satış maliyetlerinin hesaplanmasında ve üretim sürecine ilişkin muhakemede sabit maliyetler yerine değişken maliyetler kullanılır. Bu amaçla, mevcut kabiliyetle üretilecek malın miktarı ve kullanılacak işleme şekli konusunda yardım sunar (https://publikation.msg.group).

\section{Faaliyet Tabanlı Maliyetleme}

Planlama, dağıtım ve pazarlama gibi aşamalarda katlanılan maliyetler ihmal edildiğinden, geleneksel maliyet yöntemini kullanan, özellikle çok sayıda ve çeşitte mal üreten firmaların geleneksel maliyetlendirme sisteminde maliyet tahminlerinde bazı sorunlar olduğu kaydedilmiştir. Kar marjının bazı mallar için yüksek, bazı ürünler için düşük olması koşuluyla tersi de söz konusu olabilir. Bu nedenle, geleneksel maliyetlendirme sisteminin sınırlamalarını düzeltmek için faaliyet tabanlı bir maliyetlendirme modeli oluşturulmuştur; ancak geleneksel maliyetlendirme modelini kullanan bir kuruluşun yüksek karlılığı, yeni bir maliyetlendirme modeline ihtiyacı olmayacağı olarak da görülebilir. Ancak hem yöneticilerin hem de muhasebe departmanının bu durumun masrafları konusunda şüpheci olması gerekebilir. Modeli dahil etmek için muhasebe ve üretim bölümleri birbirleriyle iş birliği içinde olmalıdır. Ayrıca çok sayıda ve çeşitlilikte ürün üreten bir organizasyonda, üretim sürecinde ihtiyaç duyulan bilgilerin kolaylıkla 
elde edilebilmesi için bir bilgi ağının kurulması gerekir (Gürdal, 2007, ss.108-120).

Faaliyet tabanlı bir maliyetlendirme modeline duyulan ihtiyacin bir başka açıklaması da genel üretim maliyetlerinin, üretim maliyetleri içindeki oranının artmasıdır. Genel imalat maliyetlerindeki artış, malların maliyetini belirlese de lojistik kullanımı ve yükleme süreleri için yeni yöntemlerin kullanılmasina neden olur. Faaliyet tabanlı maliyetleme modeli de oluşturulan modellerden biridir (Unutkan, 2010, s.104).

Faaliyet tabanlı maliyetleme modeli, genel üretim maliyetlerini sağlıklı bir süreçle ücretlendirmek için tasarlanmış bir modeldir. Model, işletmelerin kaynakları kullandığını ve şirketlerin maliyetlere katkıda bulunduğunu öne sürer. Daha sonra dezavantajları nedeniyle farklı tekniklerle geliştirilmiştir.

Faaliyet tabanlı maliyetleme modelindeki zayıf yönler aşağıda belirtildiği gibidir. Bu yönler: ki şekilde tanımlanmaktadır: (Kaplan ve Anderson, 2007, s.59)

1. Faaliyet tabanlı maliyetleme modelinin oluşturulması için işgörenlerle yapılan görüşmeler ile inceleme süreci maliyetli olmakta ve uzun zaman almaktadır.

2. Faaliyet tabanlı maliyetleme modelinin oluşturulması için kullanılan veriler, özneldir ve geçerliliğini doğrulamak kolay değildir.

3. Verilerin depolaması, işlenmesi ve raporlanması maliyetlidir.

4. Faaliyet tabanlı maliyetleme modeli, yerel bazda kullanılmaktadır. $\mathrm{Bu}$ nedenle işletmenin kârlılık fırsatlarını birleştiren bir bakış açısı sağlamaz.

5. Faaliyet tabanlı maliyetleme modellinin güncelleştirilmesi zordur.

6. Faaliyet tabanlı maliyetleme modeli, kullanılmayan kapasiteyi göz ardı etmektedir. Bu nedenle teorik olarak doğru değildir.

Faaliyet tabanlı maliyetleme modelindeki kilit noktalar, maliyetlerin faaliyetler nedeniyle ortaya çıkması ve kaynakların faaliyetler nedeniyle tüketilmesidir (Gürdal, 2007, ss.118-120). Faaliyet tabanlı maliyetleme modelini iyi bir hale getirmek için ise;

1. İşletmede yapılan faaliyetler tanımlanmalıdır. 
2. Ortaya çıkan kaynak maliyetleri, faaliyet (maliyet) havuzlarına doğrudan veya bir dağıtım anahtarı (kaynak etkeni) kullanılarak dolaylı olarak dağıtılmalıdır.

3. Kaynak maliyetleri, faaliyet havuzlarından mamullere veya diğer maliyet kalemlerine faaliyete dayalı olarak dağıtılmalıdır (Aktaş, 2013, s.58).

Yukarıdaki fikirler incelendiğinde dağıtımın iki aşamada gerçekleştiği söylenebilir. gösterilebilir. İlk aşamada; kaynak maliyetleri havuzlarda toplanır. İkinci aşamada; havuzlarda elde edilen toplanan faaliyet maliyetleri, maliyet kalemlerine dağıtılır. Model aşağıdaki şekilde görülmektedir.

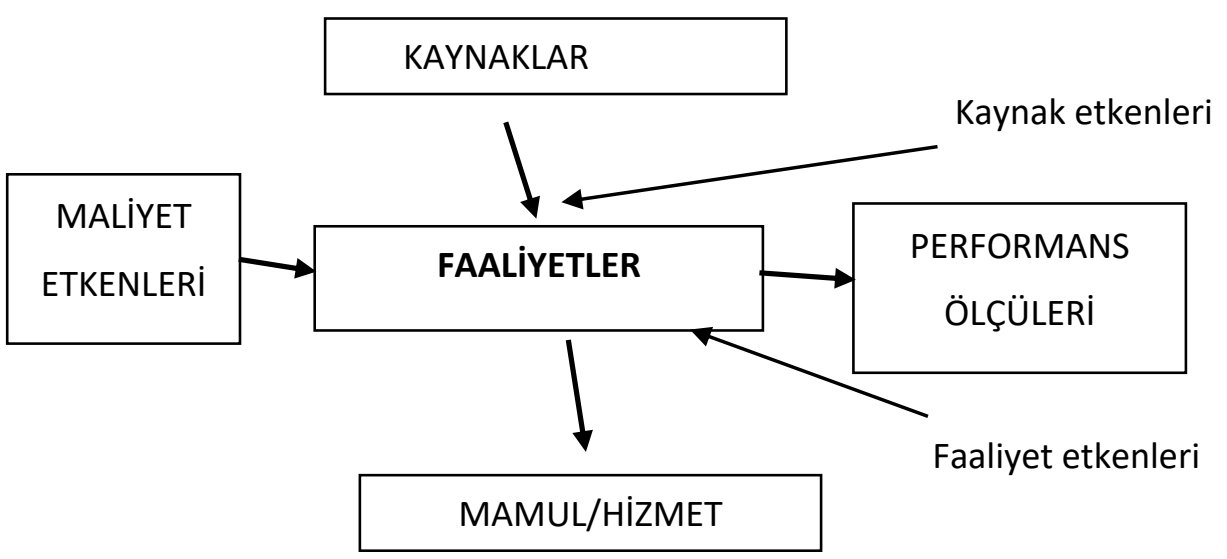

Şekil 1. Faaliyet Tabanlı Maliyetleme Modeli Kaynak: Kaygusuz ve Dokur, 2009, s.557-558.

Bu modelin uygulanması için;

1. Planlama,

2. Eğitim,

3. Kararlar için gerekli olan faaliyetlerin belirlenmesi ve açıkça ortaya konulmasi,

4. Faaliyetlerin, faaliyet merkezlerinde toplanması,

5. Maliyet unsurlarının belirlenmesi,

6. Maliyetlerin analiz edilmesi, 
7. Maliyet kaynaklarının belirlenmesi,

8. Maliyet akım tablosunun hazırlanması ve elde edilen bilgilerin bu tabloya işlenmesi,

9. Sistemin sürekli hale getirilmesi, adımlarının uygulanması gereklidir.

$\mathrm{Bu}$ adımlar tamamlanırsa arak faaliyet tabanlı maliyetleme modeli, işletmede kurulmuş olur (Cooper ve Kaplan, 1988, s.98).

Kaynak Tüketim Muhasebesi Modeli ile Alman Maliyet Muhasebesi Modelinin Karşılaştırılması

Alman Maliyet Muhasebesi modeli, bir yönetim mekanizması olarak kullanılır ve maliyet kontrolü ile ve fayda ölçüm amaçları için kullanılan bir maliyetleme yöntemidir. Değişken ve sabit maliyetlerin maliyet merkezlerine bölündüğü ve her çıktıdaki büyümenin değişken maliyetlerde orantılı olarak arttı̆̆ı, dolayısıyla doğrusal maliyetlere eşit olduğu varsayılır. Benzer şekilde, kaynak kullanımına yönelik muhasebe modeli sabit ve göreceli olarak bölünmüştür (değişken maliyetler. Maliyetler, ayrıca her iki sürüm için de standart başlangıç noktasıdır. Alman Maliyet Muhasebesi yaklaşımının faydaları, daha kesin sonuçlar üretmesi ve planlanan kapasite değişikliklerinin daha kolay fark edilmesini sağlamasıdır.

Her iki modelde de mevcut olup kullanılmayan kaynaklar nedeniyle kaynaklanan maliyetler, göz ardı edilmemiştir. Alman Maliyet Muhasebesi Modeli, kapasite odaklı bir yaklaşım seçerek kapasite ölçümü ve kontrolüne odaklanır. Kaynak kullanımının muhasebesi hem kabiliyete hem de operasyona bağlıdır. Kapasite analizi yönetimi ve süreç analizi yönetimi ile de birlikte uygulanmaktadır (White, 2009, s.71).

\section{Kaynak Tüketim Muhasebesi Modeli ile Faaliyet Tabanl Maliyetleme} Modelinin Karşılaştırılması

Faaliyet tabanlı maliyetleme modelinde; verileri depolamak, işlemek oldukça pahalı, güncelleme yapmak zordur ve kararlar işletmenin bütününe yönelik olarak alınamaz, atıl kapasite göz ardı edilir. Modeldeki bu eksikliklerin giderilmesi için farklı yöntemler 
önerilmektedir. Kaynak tüketim muhasebesi modeli de bu eksiklikleri tamamlamakta ve kaynakların daha doğru kullanılmasını sağlamaktadır (Aktaş, 2013, s.59). Faaliyet tabanlı maliyetleme modeli ile kaynak tüketim muhasebesi modelinin arasındaki temel farklılığı aşağıdaki Şekil 2' de görebiliriz.
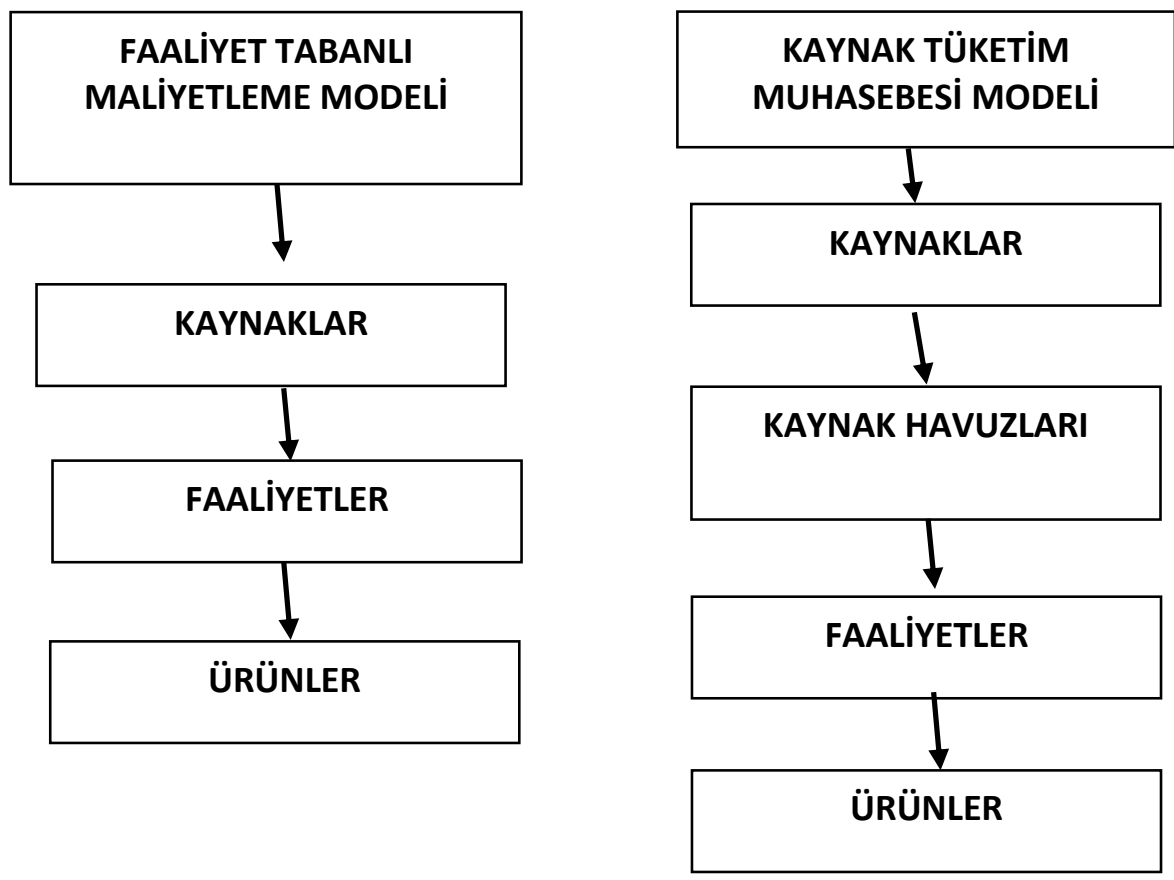

Şekil 2. Faaliyet Tabanlı Maliyetleme Modeli ile Kaynak Tüketim Muhasebesi Modeli Karşılaştırması

Kaynak: Wegmann, 2009, s.14.

Kaynak tüketim muhasebesi, faaliyetlerden daha fazla sermaye kullanırken, kaynak tüketim muhasebesi kısa vadeli harcamalara ağırlık vermiş; irken faaliyet tabanlı maliyetleme sistemi uzun vadeli kaynak tüketimine önem verir. İki model arasındaki en büyük fark atıl kapasitedir. Faaliyet tabanlı maliyetleme modelinde atıl kapasite ihmal edilmekle birlikte; atıl kapasite, kaynak kullanım hesaplama modelinde çok önemlidir ve atıl kapasitenin kontrolüne ve yönetilmesine izin verir. 
Yine, uluslararası muhasebe ilkeleri, kullanılmayan kaynakların maliyetlerle ilişkilendirilmesini önleyecek olağan bir maliyetlendirme modeli önermiştir (Gökçen vd., 2011, s.129).

\section{Kaynak Tüketim Muhasebesi Modelinin Temel Unsurları}

Kaynaklar, maliyet yapıları, yerine koyma maliyetine dayalı amortisman yöntemi, miktar temelli yaklaşım ve katkı marjı gelir tablosu yaklaşımı kaynak tüketim muhasebesi modelinin temel unsurları arasındadır (Dönmez ve Başçil, 2017, s.33).

\section{Kaynaklar}

Adından da anlaşılacağı gibi kaynaklar, kaynak tüketim muhasebesi modelinin temelini oluşturur. Kaynaklar; malzeme, ekipman, enerji ve işçilik şeklinde oluşturulabilir. Bu noktada ortak rollere sahip kaynaklar bir araya getirilir (Elmac1 ve Tutkavul, 2015, s. 84).

Yönetici kişiler için kaynakların kapasitesi ve verimli kullanımı oldukça önem teşkil eder. Kaynak tüketiminde oluşan sürece ait model aşağıdaki şekilde gösterilmektedir:

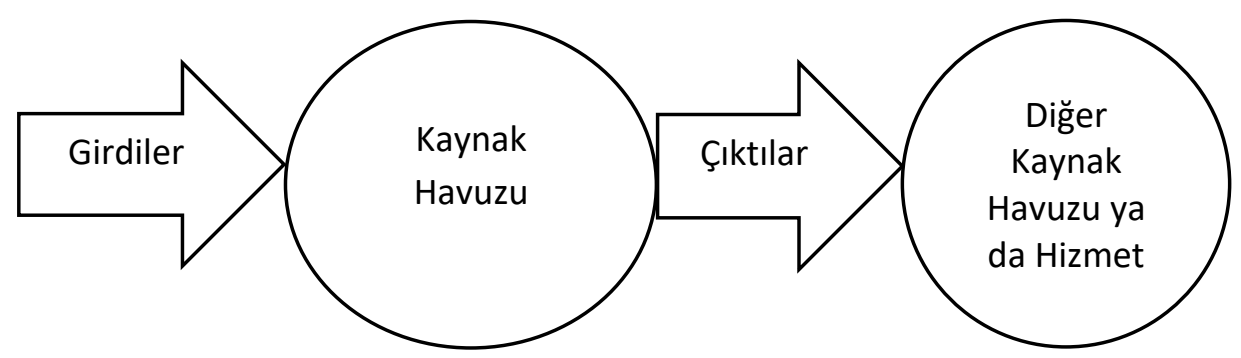

Şekil 3. Kaynak Tüketim Muhasebesi Modelinde Girdiler-Çıktılar Kaynak: White, 2009, s.65.

Malzeme, iş gücü, enerji, makine vb. şeklinde oluşan girdiler Şekil 3'te görülmektedir. Oluşan kaynak havuzlarında temel üretim, gider yeri ve yardımcı gider yerlerine dağıtılır. Elde edilen veriler bir başka kaynak havuzunda tekrardan toplanabilir veya nihai ürün ya da hizmete 
ulaşmış olabileceği ifade edilir. Oluşan bu süreç, KTM (Kaynak Tüketim Muhasebesi) modelinin en basit gösterimlerinden biridir.

Aynı örneği KTM'ye dahil etmek için bazı ek ayrıntılara ihtiyaç duyulur. Bu ek bilgi, kaynaklar, kaynak havuzlarının teorik kapasiteleri, beklenen veya mevcut kapasite (çıtıtıarı) ve kaynakların maliyet davranışı için geçerli olacaktır. Öncelikle, kaynakların maliyetlerinin birinci seviyede elde edileceği kaynak havuzlarına karar vermek önemlidir. KTM kaynak havuzu, birbirine yakın kaynaklardan oluşur ve belirli bir çıktı oluşturmak için kaynak havuzları tarafından kullanılan girdiler (ve girdi maliyetleri) hakkında bilgi toplar. Maliyetlerin aktarımı için kaynak havuzları kullanılır ve maliyet kalemleri tarafından tüketilen hizmet miktarı esas alınarak gider tahsisleri yapılır (Aktaş, 2013: 68-69)

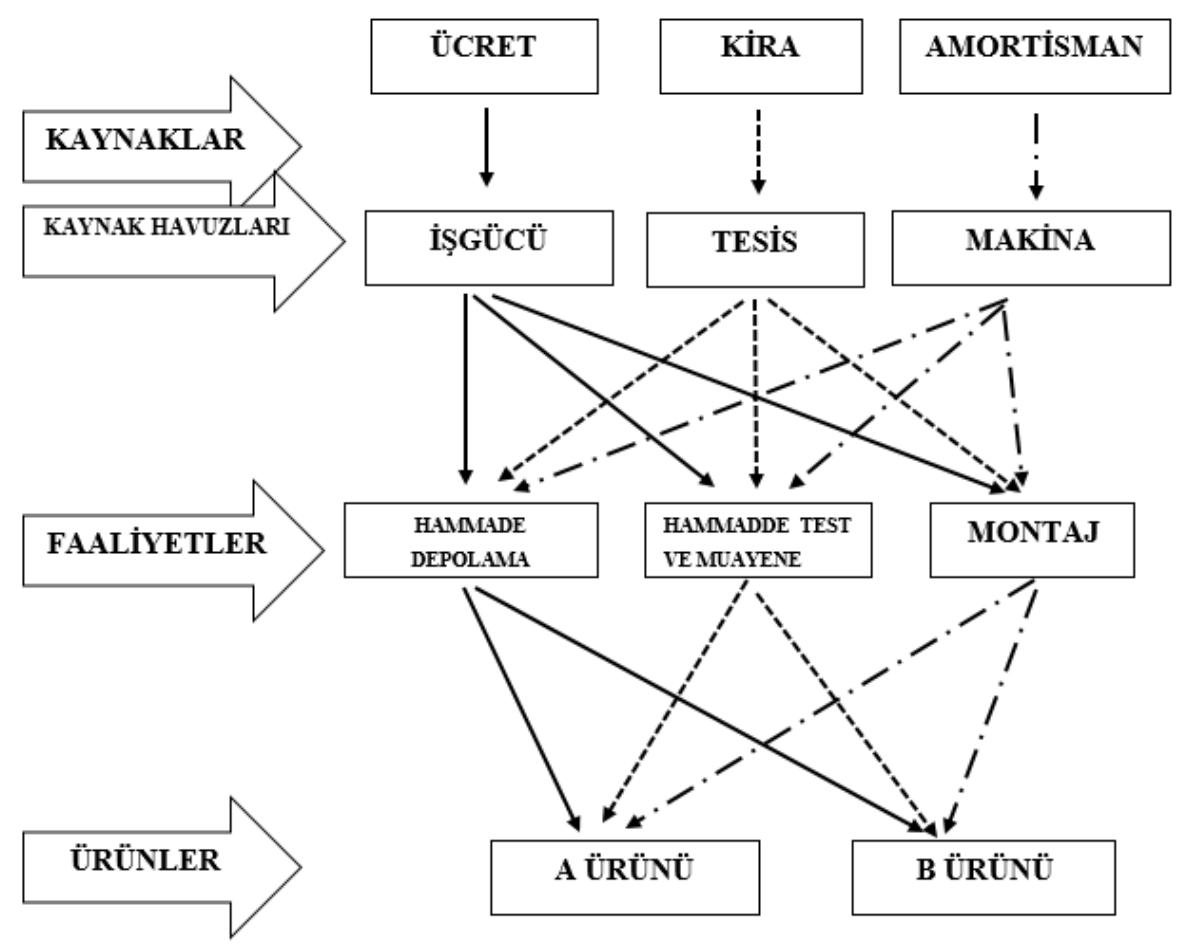

Şekil 4. KTM İşleyişi 


\section{Maliyet Yapıları}

Genel olarak, işletmelerde üretim sürecinin ürettiği kaynaklar tek bir çekirdekte depolanır. Farklı özniteliklere sahip malların farklı kaynak havuzlarında toplanarak gruplanması, maliyetleri daha kesin bir şekilde ölçmeyi mümkün kılar. Bu yaklaşım, kaynak havuzlarının oluşturulmasını ve kaynak maliyetlerinin gruplandırılmasını kolaylaştırır. Herhangi bir sermaye havuzunda tahakkuk eden maliyetlerin ana maliyetler olduğu bilinmektedir. Buradan farklı bir havuza atanan kaynaklar da ikincil maliyetler olarak adlandirılır (Tutkavul, 2016, ss.126-127; Cengiz, 2012, s.225). Maliyet merkezinde bulunan kaynak havuzlarında oluşturulan birincil maliyetler, kontrol açısından ilk sırada yer alır. Maliyet merkezlerine geçiş sırasında veya maliyetlerin yansıtılması sırasında ortaya çıkan ikincil maliyetler de ikincil etkiye sahip olacaktır. Ana ve ikincil maliyetler değerlendirildikten sonra, sabit ve orantısal (değişken) maliyetlere ayrıldığı ifade edilir. Dağıtım, kaynak havuzunun çıtıları dikkate alınarak yapilır (Kurtlu, 2016, s.5).

Kaynak tüketiminin muhasebeleştirilmesinde, kaynak maliyetleri üç temel özelliğe göre ölçülür: maliyet yapısı, yeterlilik ve kapasite. Maliyet yapısı, şirkette kullanılan kaynağın özelliklerini gösterir. Bakım ve onarım, enerji, yedek parça maliyetleri gibi pek çok şeyden oluşur. Çalışanların deneyim düzeyi, iyi hazırlıkları ve makinelerin verimliliği sertifikasyon işlevini tamamlar. Kaynak tüketiminin muhasebeleştirilmesinde kapasite ise üç başlık altında incelenmektedir. Birincisi üretken kapasitedir. Üretken kapasite, ana amaç doğrultusunda üretim yapılması veya hizmet verilmesidir. Ana amacın yerine getirilmesinde talep eksikliğinden ya da fazla kapasite ile üretim planlaması sebebiyle oluşan kapasite ise atıl kapasitedir (Sözen, 2017, s.239).

Geleneksel maliyetlendirme sisteminde sadece kayıt, süreç görünümleri ve üretim görünümleri dikkate alınırken günümüzde kaynak tüketimine dayalı bir muhasebe sistemi kullanılmaktadır. Aşağıdaki tabloda yaşanyan gelişmeler yer alır. 
Tablo 1. Maliyetleme Süreçleri Olgunluk Dönemleri

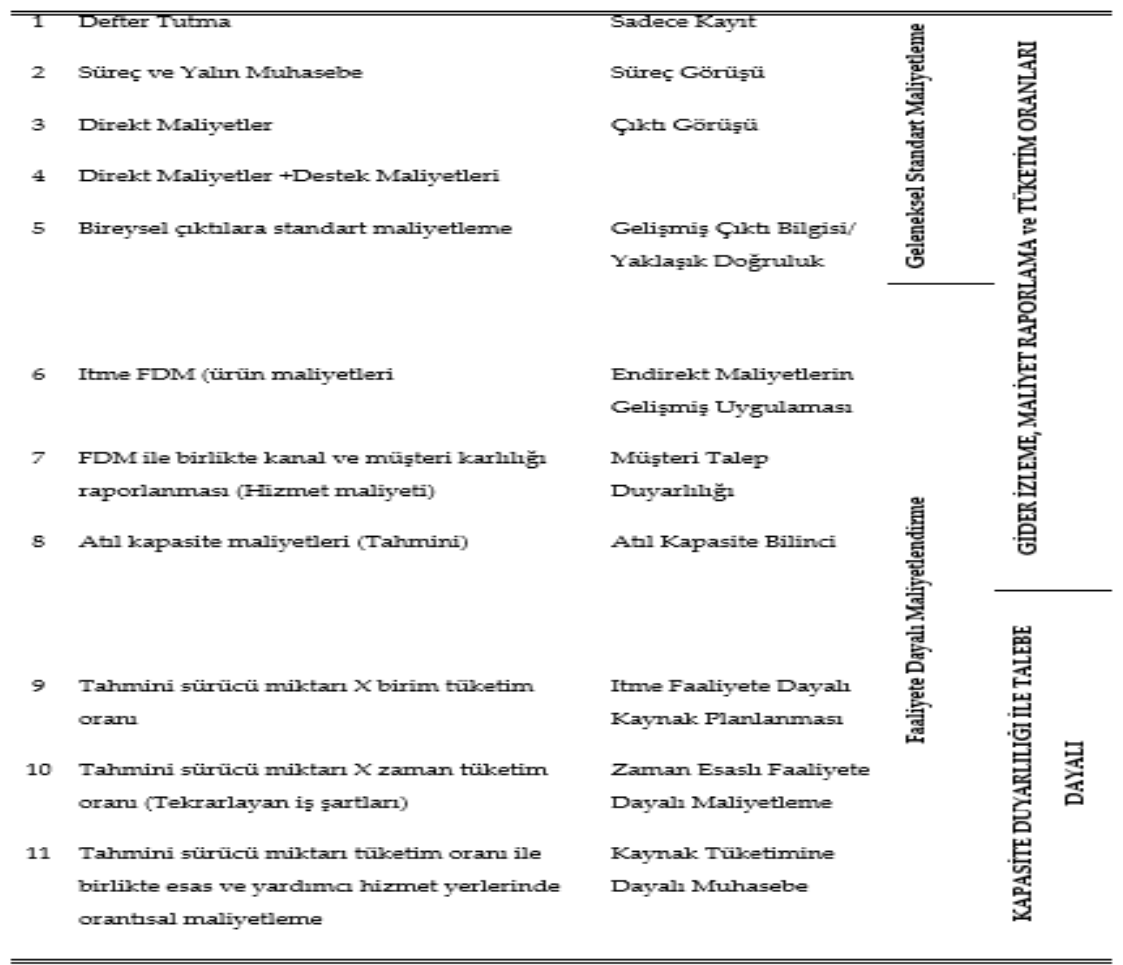

Kaynak: Erkuş ve Aksu, 2014, s.20

Tablo 1.'de, maliyetleme süreçlerinde yaşanan gelişmeler geleneksel maliyetleme modelinden kaynak tüketim muhasebesine kadar aşama aşama yer almaktadır. Muhasebe tutma, masrafların doğrudan yüklenmesi, tahmini hesaplanabilir maliyetler gibi kolay seviye tahminleri, geleneksel maliyetleme modellerinde oluşturulmuştur. Günümüzde endirekt maliyetlerin ölçülmesi, tüketici taleplerinin dikkate alınması, kullanılmayan gücü azaltmaya çalışma, zamanın değerini anlama ve maliyetlere enerji yükleme gibi çok karmaşık aşamalardan oluşmaktadır. Kaynak tüketim muhasebesi modelinde, harcın kullanılan sermayeye ödenirken malın maliyeti olduğu varsayılırken, kullanılmayan kaynağın maliyeti ise zaman maliyeti olarak kabul edilir (Tse ve Gong, 2009, s.439). 


\section{Miktar Temelli Yaklaşım}

Miktar, kaynak tüketim muhasebesi modelinin temel taşıdır. Hesaplamalar parasal olarak değil, miktar bazında yapılır. Diğer maliyetlendirme şablonlarından da farklıdır (Dönmez ve Başçil, 2017, s.35). Üretim hacmi dikkate alındığında, kaynak kullanımı ve maliyet ürünlerine daha fazla odaklanılır. Kaynak kullanımı ve gider unsurları dikkate alınır, böylece tüketim hacmi ve tüketim değeri bağımsız olarak ölçülebilir. Diğer bir avantajı ise, kapasite analizinin yapılabilmesidir. Kaynak maliyetleri kullanıldıkça havuzlara tahsis edilir ve böylece kapasite analizine olanak sağlar (Cengiz, 2012, s.229).

\section{Yerine Koyma Maliyetine Dayalı Amortisman Yöntemi}

Maliyetleme modellerinin bir kısmı özellikle geleneksel maliyetleme modelleri, büyük defter kayıtlarında bulunan bilgilerden yola çıarak amortisman hesaplamaktadır. Hesaplanan bu amortismanlar ekonomik açıdan gerçekliği yansıtmaz; çünkü tarihi maliyetler üzerinden işlem yapılmaktadır. Bu nedenle gelişmiş bir maliyet modeli olan Alman Maliyet Muhasebesinde olduğu gibi tarihi maliyetler değil, yerine koyma maliyetleri kullanılmalıdır. Böylece güncel üretim maliyetleri oluşturulacak ve günümüz teknolojisine uygun olmayan araç gereçlerde elden çıkarılacaktır. Geleneksel muhasebe sisteminde faydalı ömrü tamamlanmış, ayrılan amortisman miktarı tamamen bitmiş olan eski makinelerle üretim yapılması, satış kârının yüksek olarak hesaplanmasına neden olmaktadır. Geleneksel muhasebe sisteminde bu sorun olmamaktadır. Kaynak tüketim muhasebesi modeli bu sorunun önüne geçmektedir (Cengiz, 2012, s.229-230).

\section{Katkı Marjı Gelir Tablosu Yaklaşımı}

Şirketlerin yönetim kararlarını alırken dikkate aldığı çeşitli hususlar vardır. Yöneticiler, kaynak tüketim muhasebesi modeli veya Alman maliyet muhasebesi modelini seçen bir kuruluşun katkı marjı gelir tablosunu kullanır. Planlama ve karar verme açısından oldukça faydalı olan bu tablo, iç yöneticiler tarafından da kullanılmaktadır. Orantısal ve sabit işletme giderleri, katkı payı mali tablolarının hazırlanmasına dahil edilir. Sonuç olarak, maliyetlerin dağıtımına ilişkin bir açıklama da 
düşünülebilir. İki tabloda da dönem net kârı veya zararı değişiklik göstermeyecektir, ancak katkı marjı gelir tablosunda maliyet bilgileri değişkenliğine göre sıralanır. Örnek bir katkı marjı gelir tablosu Tablo 2.'de gösterilmektedir:

\section{Tablo 2. Katkı Marjı Gelir Tablosu}

\begin{tabular}{l|l|l}
\hline & Toplam (TL) & Birim (TL) \\
\hline Satış & x.xxx.xxx & xx \\
\hline (-) Değişken Giderler & xxx.xxx & xx.xx \\
\hline Katkı Payı & x.xxx.xxx & xx.xx \\
\hline (-) Sabit Giderler & x.xxx.xxx & \\
\hline Faaliyet Karı/Zararı & xx & \\
\hline
\end{tabular}

Kaynak: https://tr.routestofinance.com

Yaklaşımın bir diğer avantajı da marjinal kar-zarar bilgisi sunmasıdır. Nedensellik ilkesine göre ortaya çıkan kar-zarar bilgisi, işletmedeki sabit ve orantılı maliyetleri ve ayrıca devredilebilir maliyetleri gösterir. Tablo 3.'de kar-zarar tablosu yer alır.

Tablo 3. Kâr-Zarar Tablosu

\begin{tabular}{l|l|l}
\hline Kar-Zarar Tablosu & Marjinal Maliyet & Atanabilir Maliyet \\
\hline Gelir & x.xxx.xxx & xxx.xxx \\
\hline (-) Ürün Maliyetleri & xx.xxx & xxx.xxx \\
\hline Ürün Karı & x.xxx.xxx & xxx.xxx \\
\hline (-) Dağıtım Kanalları Maliyetleri & x.xxx & xxx.xxx \\
\hline Dağıtım Kanalları Karı & xx.xxx & xx.xxx \\
\hline (-) Müşeri Hizmetleri Maliyetleri & $\mathrm{xx.xxx}$ & $\mathrm{xx.xxx}$ \\
\hline (-) Müşteri Hizmetleri Atanabilir Maliyetleri & - & $\mathrm{x.xxx}$ \\
\hline Müşteri Hizmetleri Karı & $\mathrm{xxx.xxx}$ & $\mathrm{x.xxx}$ \\
\hline (-) Bölgesel Atanabilir Maliyetler & - & $\mathrm{xx.xxx}$ \\
\hline Bölgesel Kar & $\mathrm{xxx.xxx}$ & $(\mathrm{x.xxx})$ \\
\hline (-) Şirket Seviyesinde Atanabilir Maliyetler & - & $\mathrm{xx} . \mathrm{xxx}$ \\
\hline Faaliyet Sonucu & $\mathrm{xxx.xxx}$ & $(\mathrm{xx.xxx)}$ \\
\hline
\end{tabular}

Kaynak: White, 2009, s.70.

\section{Sonuç}

1980'lerden bu yana, yönetim muhasebesinin amaçlanan işlevleri yerine getirememesinin eleştirisinin ardından birçok yeni yönetim ve maliyet muhasebesi yaklaşımı tanıtılmaya başlanmıştır. Gerçekte, alternatif çözüm arayışı hâlihazırda devam etmektedir ve farklı ortamlarda çeşitli yönetim kararları için ilgili ve güvenilir maliyet bilgileri sağlamak 
amacıyla için yeni yaklaşımlar yaratılmaktadır. KTM, bu araçlardan biri olarak yöneticilere açık hale getirilmiştir.

KTM, maliyetlerin dağıtımı için kaynaklara odaklanır; FTM'nin aksine, kaynakları doğrudan faaliyetlere atamaz; ancak bunları kaynak havuzlarında toplar ve bunları yalnızca faaliyetlere ve oradan da maliyet nesnelerine dağıtır. Sonuç olarak, çok fazla kaynak değişkenine sahip görevlere çok miktarda kaynak tahsis etme sürecini etkinleştirmek, sistemin uygulanabilirliğini artırır. KTM ise kaynak havuzlarında toplanan maliyetleri önce birincil-ikincil maliyetleri, daha sonra bu iki gider sınıfını sabit orantılı maliyetler olarak gruplayarak izler. İzleme maliyetleri, en azından belirli bir derinlikte bazı özel gider ayrıntıları anlamına gelecektir. Böylelikle farklı kararlarda çeşitli harcama bilgileri sunan bir araç olarak, yöneticilerin karar alma süreçlerinde muhasebe bilgi sisteminden daha verimli yararlanmasını sağlar.

KTM'nin en önemli özelliklerinden biri, atıl kapasite bilgisini sağlamasıdır. KTM tarafından verilen atıl kapasite, işletmenin performansının ve rekabet gücünün artmasına yol açacaktır. KTM aslında FTM'nin eksikliklerini ortadan kaldıran bir araç olarak görülürken, FTM'den çok daha kapsamlı olduğu ifade edilir. Yöntem, bir yandan FTM'nin zorluğunu azaltırken, diğer yandan maliyetleri çeşitli açılardan tanımlamak ve izlemek için çok kapsamlı bir prosedür içerir.

Bu şekilde ayrıntılı bir sistemin üretilmesi, uygulanması ve gerektiğ durumda değiştirilmesi FTM kadar zor, kapsamlı ve pahalı görünür. Bu şekilde kapsamlı ve karışık sistemlerin uygulanabilmesi sadece maliyetli bilgisayar programları (Kurumsal Kaynak Planlaması - ERP) ile mümkün olduğu belirtilir. KTM, işletmelere kendine özgün ayrıntılı maliyet takipleri ile sağlıklı bir maliyet kontrolü ve doğru maliyet bilgileri sağlar. Fakat en az FTM kadar kamaşık olması, çok detaylı hatta anlaşılması güç olabilecek kadar ayrıntılı bilgi sunması ve uygulanabilmesinin oldukça yüksek maliyetli ERP sistemlerine ihtiyaç duyulmasının ise dezavantajları olarak da gösterilir. Oluşan bu dezavantaj sebebiyle de uygulama düzeyinin düşük kalabileceğinden bahsedilir. 


\title{
EXTENDED ABSTRACT
}

\section{Influence of Accounting Information System and Resource Using Accounting on Management Decisions

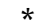

\author{
Kadir Aydin \\ Adryaman University
}

The continued common use of the conventional 'peanut butter' approach to cost allocation is somewhat shocking considering that it has been questioned for more than 30 years. Studies have shown that up to $80 \%$ of businesses prefer to use conventional costing approaches (or turned back to them), considering the lack of satisfaction for many accountants of the companies with relying on their cost accounting system for the purposes of decision making (Sharman 2003b). Change, however, comes slowly, particularly when the alternatives are new, confounding and costly in such divergent ways.

For example, advocates of activity-based costing (ABC) base their claims on the view that all costs, including power costs, are volatile over the long term. The ABC model captures this uncertainty by assigning prices to goods in proportion to the anticipated long-term demand for expensive services. On the other hand, the advocates of the Restriction Principle (TOC) have a very short-term approach and conclude that the cost of most commodities is constant and inescapable. As a consequence, the TOC model typically assigns only variable material costs to goods while at the same time trying to maximize the throughput (i.e. contribution margin) of fixed resource capacities that constrain the overall method.

In companies, processes such as collecting, monitoring, classifying, summarizing data from all organizational activities, viewing and evaluating financial events are carried out by Information Technology. In the accounting management system, managers who use information technologies and accounting records collect some information about transactional accounting system information and internal financial reporting system and operations. The accounting information system 
(MBS) allows managers to distinguish controllable events from uncontrollable events with cost-benefit analysis.

Accounting information system creates management information system technology and is an automatic information system. Financial activities are found in each branch of the organization. In the study, it deals with the accounting information system and management information system conceptually.

It is expressed that recently, cost structures and models according to manufacturing technology and production models have been evaluated as a need for manufacturing companies. From a causal point of view, the use of traditional systems with cost and control accounting is not sufficient or appropriate for the current. Resource consumption accounting is a new approach that has been on the agenda since the early 2000s. This approach is an approach that uses the advantages of Activity Based Costing and is integrated with the German Cost Accounting's perspective on resources and accepts that the basis of costs are resources.

The literature review method, one of the scientific research methods, was used in the study.

Academic research is built on the findings of previous scientific studies, ideas expressed and approaches addressed. In academic studies conducted as a continuation of each other, previous studies related to the research subject should be reviewed. This process, which is called literature review in academic research, includes studies such as searching, finding, analyzing, reading, classifying, summarizing and synthesizing previously published works related to the research subject. The main purpose of the literature review and analysis is to determine the point where the previous literature has come about the subject being researched, to reveal the gaps and omissions in the literature, and to determine where our own study will fit in the previous literature. In academic studies; The purpose, research questions, problem situation, hypotheses, methods, findings and results are presented supported by the information obtained as a result of the literature review. Academic research gains a scientific depth and identity with the literature review done properly. The contribution of academic research to humanity and science varies in proportion to the importance it attaches to literature review. 
Demonstrates the fundamental mechanics of RCA relative to TOC, $\mathrm{ABC}$, and the standard costing model. Arguments favoring one strategy over the other are usually based on the time span of the decision, the complexity of the product combination and/or the complexity of the manufacturing environment. Relevance is of course, of the highest significance to an educated decision-maker.

In fact, retaining multiple costs may not be practical or desired, but it may allow management to conform to the current structures so as to satisfy diverse decision circumstances through recognizing the conceptual value of alternative approaches. The RCA tends to take all the time horizons listed previously where the required technical climate and management skills are available. RCA's relative and fixed cost division can help short-term marginal decisions and RCA's resource capacity insights can support decisions that affect or depend on capability criteria for the long term.

\section{Kaynakça / References}

Acar, D. ve Özçelik, H. (2011). Muhasebe bilgi kalitesini etkileyen kritik başarı faktörleri. Muhasebe ve Finansman Dergisi, 49, 10-23.

Aksu, İbrahim. (2013). 'Kaynak tüketimine dayalı muhasebe: Bir örnek uygulama' , E-Journal of New World Sciences Academy ,8(4), 165-182.

Aktaş, R. (2013). 'Yeni bir maliyet ve yönetim muhasebesi yöntemi olarak kaynak tüketim muhasebesi', Muhasebe ve Finansman Dergisi, 58, 5576.

Cengiz, E. (2012). Gelişmiş bir maliyetleme yaklaşımı olarak kaynak tüketimi muhasebesi', Muhasebe ve Bilim Dünyası Dergisi, 14(1),215233.

Cooper, R., and Kaplan, R. S. (1988). How cost accounting distorts product costs. Strategic Finance, 69(10), 20.

Dönmez, A. ve Başçil, G. (2017). Kaynak tüketim muhasebesi: Bir mobilya üretim işletmesinde uygulama, Mali Çözüm Dergisi, 139, 29-56.

Elmacı, O. ve Tutkavul, K. (2015). Sürdürülebilir üstünlük elde edebilme bağlamında çevresel maliyetlerin analizi ve çevresel maliyetlerin raporlanmasında kaynak tabanlı maliyetleme model önerisi, Muhasebe Bilim Dünyası Dergisi, 17(1), 75-110. 
Erkuş, H., Aksu, İ. Ve Turan, E. (2014). Kaynak tüketim muhasebesinin diğer maliyet sistemleri ile karşılaştırılması, Muhasebe ve Vergi Uygulamaları Dergisi,2,15-36.

Ertaş, F. C. (2016). Muhasebe bilgi sistemi ve organizasyonu. 4. bsk., Ankara, Seçkin Yayıncılık.

Fevzi, S., Nurten, E., Melih, E., Kerim, B., Ergün, K., ve Adnan, S. (1998). Muhasebe bilgi sistemi. Anadolu Üniversitesi Yayınları, (963).

Gökçen, G., Ataman, B. ve Çakıcı, C. (2011). Türkiye finansal raporlama standartları uygulamaları, Türkmen Kitabevi, İstanbul.

Gürdal, K. (2007). Maliyet yönetiminde güncel yaklaşımlar, Ankara: Siyasal Kitabevi.

Kamu Gözetimi Kurumu (2018). Finansal raporlamaya ilişkin kavramsal çerçeve, 27 Ekim 2018 tarihli ve 30578 sayılı Resmi Gazete.

Kaplan, R. S. And Anderson, S. R. (2007). The innovation of time-driven activity-based costing, Cost Management,21(2), 5-15.

Kaygusuz, S. Y. ve Dokur, Ş. (2009). Maliyet muhasebesi, Bursa: Dora Yayınevi.

Kurtlu, A. E.. (2016). 'Kaynak tüketim muhasebesi: silah fabrikası örneği', Niğde Üniversitesi İktisadi ve İdari Bilimler Fakültesi Dergisi, 9(3), $1-14$.

Ömürbek, V. (2003). Kurumsal kaynak planlamasinda muhasebe bilgi sisteminin rolü: Gıda sektöründe uygulama (Doctoral dissertation, Sosyal Bilimler).

Özyapıc1, H. (2012). Resource consumption accounting and its application in a healthcare institution', Çukurova Üniversitesi, Sosyal Bilimler Enstitüsü, İşletme Anabilimdalı, Doktora Tezi.

Perkins, D. and Stovall, S.O: (2011). 'Resoruce consumption accounting: Where does it fit?', The Journal of Applied Business Research, 27, .5.

Romney, M. B. and Steinbart, P. J. (2015). Sistem informasi akuntansi. Jakarta: Salemba Empat.

Sevim, Ş. (2008). Muhasebe bilgi sistemi. (Editör F. Sürmeli), Anadolu Üniversitesi Yayın, (1736).

Sharman, P. A. (2003b). The case for management accounting, Strategic Finance, 85(4), 42-47. 9. Webber, Sally, and

Sözen, M. (2017). Kaynak tüketim muhasebesinin gelişim süreci, maliyet avantajları ve teorik bir uygulama', U.Ü. Sosyal Bilimler Enstitüsü Dergisi, 10(2), 229-254. 
Şahin, M. (2007). Yönetim bilgi sistemi (Vol. 784). Anadolu Universitesi.

Tse, Michael S. C. Maleen Z. Gong. (2009). 'Recognition of idle resources in timedriven activity-based costing and resource consumption accounting models', JAMAR, 7(2), 41-54.

Tutar, H. (2006). Yönetim bilgi sistemi. Seçkin Yayıncllık.

Tutkavul, K. (2016). 'İsletmelerin sürdürülebilir rekabet gücü ve rekabet üstünlüğ̈̈ sağlamada verecekleri stratejik kararların kaynak tüketim muhasebesi modeliyle doğrulanmasına yönelik amprik bir çalışma', Dumlupınar Üniversitesi, Sosyal Bilimler Enstitüsü, İşletme Anabilimdall, Doktora Tezi.

Türel, A. (2018). Muhasebe bilgi sistemleri. İstanbul. Çağlayan Kitabevi.

Unutkan, Ö. (2010). Faaliyet Tabanlı Maliyetleme Sistemi ve Bir Uygulama, Mali Çözüm Dergisi, 97, 87-106.

Wegmann, G. (2009). 'The activity-based costing method: Development and applications', The Icfai University Journal of Accounting Research,8(1) ,7-22.

White, L. (2009). Resource consumption accounting: Manager-focused management accounting. Journal of Corporate Accounting $\mathcal{E}$ Finance, 20(4), 63-77.

Zhang, Q., Dong, X., and Huang R. (2011). The application of resources consumption accounting in an enterprise. artificial intelligence, management science and electronic commerce (AIMSEC), 2011 2nd International Conference, Conference Publications, s.2481-2484.

\section{Kaynakça Bilgisi / Citation Information}

Aydın, K. (2021). Muhasebe bilgi sistemi ve kaynak kullanim muhasebesinin yönetim kararlari üzerindeki etkisi. OPUSUluslararası Toplum Araştırmaları Dergisi, 18(39), 1001-1027. DOI: 10.26466/opus.833494. 